\title{
Estratégias dos Estados nacionais diante do processo de globalização
}

\author{
JACOB GORENDER
}

G

LOBALIZAÇÃo E REVOLUÇÃo TECNOLÓGICA são processos objetivos e conjugados. A globalização caracteriza o atual período de evolução do sistema capitalista. Representa a continuação da expansão mundializante originariamente inerente ao capitalismo. Continuação que é, contudo, acentuação e aceleração, com manifestações na economia, na política, nas atividades culturais e nos comportamentos sociais.

A globalização tem sua base material na terceira revolução tecnológica. Esta vem avançando através da informática (computação e microeletrônica), das telecomunicações, da biotecnologia e da engenharia genética, da invenção de novos materiais etc.

Globalização e revolução tecnológica projetam para o futuro a possibilidade de uma sociedade planetária unificada. Compreensivelmente, trata-se de um futuro a longo prazo, indefinido no surgimento e indeterminado nos traços concretos. Contudo, vários aspectos atinentes a tal futuro já se evidenciam no presente.

Aspectos que suscitam reflexões dizem respeito à criação da cultura mundial, capaz de congraçar os povos mais diversos, unindo-os na mesma atividade criativa; à superação dos particularismos agressivos e das hostilidades manifestas ou latentes entre nacionalidades, etnias e raças; à abordagem das questões ecológicas como temário intrinsecamente carente de visão global.

Defrontam-se os povos com a potenciação imensa do ser humano, muito além do imaginável há pouco tempo atrás. Na perspectiva da sociedade global, colocam-se visões reconstrutivas e transformadoras como as do ecumenismo católico (teologia da libertação) e do socialismo marxista (Ianni, 1992; Boff, 1993; Ortiz, 1994).

No enfoque das tendências operantes no mundo concreto atual, afasta-se a atuação de causas finais. Ainda que a teleologia compareça como explicação para a motivação subjetiva de ações humanas, os resultados objetivos destas extrapolam o âmbito da teleologia. Assim, a globalização deve ser vista como processo submetido a determinações, porém não a fatalismos. Acidentes de percurso 
são possíveis e não são improváveis desvios de rumo. Numerosas variáveis interagem sobre o agregado de sociedades humanas coexistentes no planeta e semelhante interação permite a projeção de mais de um cenário.

\section{Ciclo econômico e condições da concorrência capitalista}

A aceleração do ritmo de avanço da globalização e da revolução tecnológica relaciona-se com os fatores depressivos em curso no sistema econômico capitalista, a partir de 1973.

Durante cerca de trinta anos após o término da Segunda Guerra Mundial, a economia capitalista mundial desenvolveu-se a taxas historicamente altas, inéditas para tão longo tempo. Foi neste período que se implementaram as técnicas keynesianas do Estado do Bem-Estar e, em geral, da intervenção e da regulação estatais nas questões econômicas. Na Europa ocidental e nos Estados Unidos, tornou-se possível e praticável o jogo de soma positiva, que incrementou os lucros das empresas, elevou as taxas de acumulação do capital e, ao mesmo tempo, trouxe melhoras sensíveis no padrão de vida dos assalariados e dos estratos sociais médios. Em muitos países do chamado Terceiro Mundo, ganhou impulso um processo desenvolvimentista que alterou parâmetros sociológicos tradicionais e suscitou expectativas otimistas aparentemente fundamentadas. No Extremo Oriente, consolidou-se nova área extraordinariamente dinâmica do capitalismo, com o Japão à vanguarda. A Guerra Fria não deixava de ter sua cota de influência em tais desdobramentos, à medida que incitava as cúpulas econômica e política dos principais países capitalistas a adotarem procedimentos dirigistas do crescimento econômico e táticas concessivas nas relações do Estado e das empresas com os trabalhadores, tendo em vista ganhar força social na competição com a União Soviética e demais países do campo socialista. Mas também estes tiveram taxas elevadas de crescimento econômico no período mencionado. Se foi uma idade de ouro para o capitalismo, conforme tem sido afirmado, também foi uma época brilhante para a experiência socialista deste século (Gorender, 1992).

Sob inspiração de Keynes, de um lado, e de Marx, do outro, o intervencionismo e o planejamento pareciam bem-sucedidos, ainda que, em ambos os lados, sérias deficiências e contradições viessem à luz. Estado intervencionista, Estado do Bem-Estar, Estado desenvolvimentista, Estado socialista - o Estado situava-se como eixo da dinâmica social, em países os mais diferenciados, durante as três primeiras décadas do pós-guerra.

O ponto de inflexão se dá em 1973, quando ocorre o primeiro choque do petróleo. Os países capitalistas mergulham numa recessão da qual saem mediante difícil adaptação às novas condições referentes à matriz energética. Mas, já no final da década dos 70, ocorre o segundo choque do petróleo. Nova e mais dura 
recessão acomete os países desenvolvidos, a começar pelos Estados Unidos, daí se difundindo para os países em desenvolvimento ou subdesenvolvidos.

Os choques do petróleo atuaram como detonadores de crises cíclicas, mas estas tiveram suas causas na expansão inflacionária da economia norte-americana, decorrente dos gastos com a guerra do Vietnã, e na crise fiscal dos Estados do Bem-Estar Social.

Em nível mais profundo, agiam tendências de longo prazo manifestas na queda das taxas de crescimento da produção e da produtividade na economia mundial e, em particular, nos países capitalistas desenvolvidos.

Como se visualiza na tabela 1 , a taxa de crescimento do PIB mundial cai significativamente a partir da década dos 70 . A tabela 2 mostra a tendência de queda da taxa de crescimento do PIB nos países industrializados.

As tabelas 3 e 4 demonstram a queda da taxa de crescimento da produtividade do trabalho e da produtividade industrial nos países desenvolvidos.

Por essas tabelas verifica-se que as tendências de queda não foram revertidas no final dos anos 80 , nem no início da década de 90, caracterizada por nova recessão cíclica.

A tendência declinante das taxas de crescimento do produto e da produtividade tem sido explicada pelo esgotamento do chamado modelo fordista de organização produtiva e da tecnologia a ele acoplada. Outra explicação não necessariamente discrepante da anterior aponta, em meados dos anos 70, o fim da fase ascendente e o início da descendente, ainda em curso, no chamado ciclo longo de Kondratieff.

A tendência declinante das taxas de crescimento da produção e da produtividade intensificou de forma significativa a concorrência entre as empresas multinacionais e, conseqüentemente, entre os países industrializados. A implementação de inovações tecnológicas, sobretudo das relacionadas com a microeletrônica, tornou-se muito mais rápida. O estudo das práticas japonesas induziu a difusão mundial do modelo toyotista de organização do trabalho e da produção.

Ao mesmo tempo, desencadeou-se nos países desenvolvidos, com maior ou menor intensidade, a campanha pela redução dos gastos sociais oficiais e pela desregulamentação dos mercados de trabalho, de bens e de serviços. A campanha inseriu-se no amplo questionamento do papel do Estado e na pressão dos grupos econômicos dominantes pela contração do âmbito de atuação estatal. Como pontos mais importantes, colocavam-se os cortes nos orçamentos previdenciários (eliminando ou reduzindo transferências oficiais) e as privatizações de empresas estatais. No plano da teoria, a influência da doutrina intervencionista de Keynes 
foi substituída pela influência da doutrina monetarista-liberal de Friedman. Esta inseriu-se na concepção mais geral, que veio a ser chamada de neoliberalismo (Anderson, 1995).

A mudança de curso da política econômica não trouxe, como já visto, a reversão da queda das taxas de crescimento da produção e da produtividade. Pelo contrário, a queda das taxas acentuou-se e é possível que o fenômeno se deva, ao menos em parte, ao desvio de proporção considerável do capital líquido para operações financeiras especulativas, de âmbito mundial. Em conseqüência, a recuperação dos níveis de lucratividade do capital foi conseguida num contexto de muito maiores dificuldades, o que, por sua vez, aguçou a concorrência interempresas e entre países industrializados.

Os países capitalistas enfrentaram a inflexão cíclica com uma vigorosa revolução tecnológica. Não conseguiram retornar aos índices de produtividade das três primeiras décadas do pós-guerra, mas lograram aplicar reajustes críticos, que permitem manter certo equilíbrio acentuadamente instável nos regimes sociais internos e nas relações internacionais.

Já os países do campo socialista, por problemas estruturais cada vez mais agudos, viram-se impotentes para enfrentar a nova fase do ciclo econômico com a revolução tecnológica. Tolhidos pela estagnação do sistema de planejamento central, ingressaram na década dos $80 \mathrm{com}$ taxas de crescimento próximas de zero ou mesmo negativas. A tentativa reformista da perestroika resultou em fracasso, culminando no desmoronamento do campo socialista e na dissolução da União Soviética.

\section{Situação e papel \\ dos Estados nacionais}

Os processos da globalização e da revolução tecnológica concretizam-se nesse quadro histórico delineado. No período atual, tais processos não anulam, nem tampouco diminue a importância dos Estados nacionais.

Costuma-se argumentar com a suposta onipotência do capital financeiro, bancário e principalmente não-bancário, no sentido de que teria relegado o Estado à condição de instituição secundária, destituída de poder intervencionista. Pode-se caracterizar tal argumento como próprio de uma concepção economicista, no caso, um economicismo financeirista.

Não se trata de contra-argumentar a partir de uma concepção, também falsa, sobre a onipotência do Estado. Dotado que seja de relativa autonomia decisória, o Estado nacional é sempre o garante de determinada organização econômica e sócio-política. Tomada em conjunto, sua atuação defende e mantém o ordenamento institucional necessário a determinada dominação de classe. 
Por maiores que sejam seu peso e sua agilidade, a atuação do capital financeiro especulativo só é concebível no quadro das relações de propriedade asseguradas pela legislação dos Estados capitalistas.

O Estado é o fiador dos direitos do capital, ao mesmo tempo incumbindo-se da legitimação política da organização social. Sem o poder legitimador e coercitivo do Estado, não haveria sequer como explicar a própria existência do capital financeiro. Do ponto de vista estritamente econômico, o Estado conserva sua força, mesmo após as mudanças liberais dos últimos tempos.

No conjunto dos países da OCDE, o dispêndio do Estado consome cerca de $50 \%$ do PIB, o que dá a cada Estado nacional enorme peso na orientação da atividade econômica do respectivo país (Anderson, 1995:16).

Conforme evidenciam os fatos, as empresas multinacionais não têm apego a limitações de caráter nacional, mas, nem por isso, são entidades descentradas. Todas são regidas por matrizes sediadas em tal ou qual Estado nacional. Dessas matrizes partem as decisões estratégicas com relação a investimentos, inovações tecnológicas de processos e de produtos, expansão para novos mercados etc. Para tais matrizes e, por conseguinte, para seus acionistas, remetem as subsidiárias vultosas somas anuais de rendimentos, que constituem item de grande significação no cômputo dos balanços de pagamentos de cada Estado nacional.

Justamente na fase atual de concorrência acirrada, as empresas multinacionais recorrem ao poder do Estado nacional, em cuja jurisdição se situam suas matrizes, visando a enfrentar os concorrentes e a influir nas decisões dos Estados nacionais, em cujas jurisdições operam suas subidiárias.

Em algumas conjunturas, empresas multinacionais de certos setores podem ter interesses divergentes ou contraditórios com relação aos dos seus Estados nacionais. Não obstante, em conjunto e a longo prazo, prevalece o acordo de interesses e o apoio mútuo. É assim que, enquanto o governo dos Estados Unidos intervém, até ostensivamente, em favor de interesses das empresas multinacionais norte-americanas, seja para assegurar-lhes supostos direitos ou contratos vantajosos, aquelas empresas multinacionais, por sua vez, atuam como órgãos da hegemonia dos Estados Unidos no atual sistema de relações internacionais (Gilpin, 1975:139-44, passim).

Jurisdição territorial, cobrança de tributos e emissão de moeda permanecem atribuições exclusivas do Estado nacional. Embora deva fazê-lo sob pressão dos agentes interessados, cabe aos Estados nacionais a regulação de parâmetros financeiros como as taxas de juros e de câmbio.

É preciso considerar ainda que as organizações internacionais de direito público hoje existentes possuem os Estados nacionais como sujeitos fundadores 
e mantenedores. É certo que os Estados nacionais não podem deixar de levar em conta as obrigações decorrentes de seus compromissos com as organizações internacionais, com os tratados em vigor e com as normas do direito internacional. Em suma, o regime internacional tem inegável força impositiva sobre cada Estado nacional, por mais poderoso que seja (Vigevani et al., 1994). Todavia, os Estados nacionais permanecem como suportes básicos de qualquer regime internacional. Sem ter esta realidade em vista, sequer se poderia entender e, muito menos, explicar o noticiário cotidiano sobre o que se passa no mundo.

O processo de globalização altera e, sob alguns aspectos, reduz os atributos de soberania dos Estados nacionais. É preciso, porém, considerar as reações destes diante das questões propostas pela própria globalização. Os Estados nacionais posicionam-se diante do processo de globalização conforme interesses de classe que expressam, empregando os meios de pressão e persuasão de que dispõem.

Sob tal enfoque, cumpre ter em mente que a globalização, uma vez que ocorre como processo capitalista, encerra em sua essência a tendência à acentuação das desigualdades entre os Estados nacionais. Não se trata de característica circunstancial ou conjuntural, mas da natureza essencial da globalização capitalista. A tendência à acentuação da desigualdade atua no sentido do aumento dos meios de influência dos Estados dos países capitalistas desenvolvidos, ao passo que enfraquece os meios de resistência dos países em desenvolvimento. São diferentes, por conseguinte, os posicionamentos diante do processo de globalização.

Enquanto obstaculizam a globalização, quando lhes é conveniente, os Estados dos países desenvolvidos a utilizam como argumento para conformar a política econômica dos Estados dos países em desenvolvimento ou atrasados. Assim, por exemplo, ao tempo em que persistem na aplicação de medidas protecionistas no comércio exterior, os Estados dos países desenvolvidos recomendam a completa liberalização do comércio exterior aos parceiros dos países mais fracos. A estes se dirige a retórica da globalização irrestrita, enquanto os países desenvolvidos põem em prática o que se poderia chamar de globalização seletiva.

\section{Blocos regionais e suas estratégias}

A concorrência entre os países industrializados e suas empresas multinacionais conduziu, na fase atual, à formação de blocos econômicos regionais. Notoriamente, os três principais dentre eles são o Tratado de Livre Comércio da América do Norte (NAFTA), a União Européia (UE) e o bloco informal do Extremo Oriente. Por conseguinte, prevalece a orientação de afirmação de interesses regionais, tendo os Estados Unidos, a Alemanha e o Japão à frente dos respectivos blocos. Os três países constituem a Tríade dominate da economia mundial 
A política de blocos encerra significação contraditória no que se refere ao comércio mundial. Por um lado, contribui para incentivá-lo, na medida em que intensifica o intercâmbio entre os membros do bloco, e deste com parceiros externos. Por outro lado, porém, permite a prática protecionista do bloco em conjunto diante dos outros blocos e, em geral, de países de fora, desta maneira conduzindo a um desvio de comércio.

Essa contradição manifestou-se nas negociações multilaterais da Rodada Uruguai. Acompanhando a tendência prevalecente no segundo pós-guerra, no sentido da ampliação do comércio mundial, as negociações se concluíram, em 1994, com reduções importantes de tarifas aduaneiras. Em vários aspectos, no entanto, mantiveram-se intocadas medidas protecionistas referentes a tarifas aduaneiras e barreiras não-tarifárias. Além do que, têm sido praticados atos duvidosos ou de evidente violação do acordo final, que criou a Organização Mundial do Comércio (OMC). Em especial, destacam-se os subsídios e outros incentivos que os países desenvolvidos concedem aos seus agricultores, com evidente prejuízo para os países do Terceiro Mundo (Noronha, 1994). Nestas circunstâncias concretas, configura-se a importância dos Estados nacionais e dos governos enquanto seus órgãos executivos.

O governo norte-americano envida esforços persistentes com vistas à implementação da estratégia de contenção do declínio da hegemonia econômica e política dos Estados Unidos. Com semelhante estratégia são coerentes, ao mesmo tempo, a criação do NAFTA (regionalização) e o apoio à fundação da OMC (globalização). Enquanto maior potência econômica do mundo, os Estados Unidos têm interesse na liberalização crescente do comércio internacional, porém isso não os impede de pôr em prática medidas protecionistas de favorecimento a setores de sua economia.

O governo dos Estados Unidos implementa uma política intervencionista de defesa dos interesses das suas empresas multinacionais, bem como do nível de emprego de sua população. É particularmente notório o contencioso entre os Estados Unidos e o Japão. Apesar de toda a pressão exercida até agora, a estratégia norte-americana tem falhado no objetivo de reduzir significativamente o déficit da balança comercial, principalmente com o Japão. Carente do apoio financeiro dos demais países desenvolvidos, os Estados Unidos não podem recorrer a retaliações radicais no âmbito comercial. Nem por isso, deixam de adotar medidas tendentes à reversão do seu continuado enfraquecimento. Ultimamente, promoveram nova e acentuada desvalorização do dólar, com o objetivo de fomentar as exportações, e forçaram acordo comercial com o Japão referente a autoveículos e autopeças (Gilpin, 1987).

Área de peso secundário para a estratégia norte-americana, a América Latina recebe pressões que induzem comportamentos consentâneos com o interesse conjuntural dos Estados Unidos em cada situação dada. 
$\mathrm{Na}$ década dos 80 , evidenciada a inadimplência da dívida externa pelos países da América Latina, a política do governo norte-americano orientou-se no sentido de proteger os bancos credores, cujas exposições financeiras os tornavam vulneráveis e passíveis mesmo de falência. Tal orientação traduziu-se na recomendação de que os países devedores da América Latina alcançassem grande superávit na balança comercial, possibilitando, portanto, o acúmulo de reservas cambiais para o serviço da dívida. Compreende-se que o Brasil, naquela década, haja comprimido fortemente suas importações, chegando a reduzir sua abertura ao comércio exterior de 10 para 5\%. A mesma conduta tiveram o México e outros países latino-americanos. A compressão das importações teve grave efeito negativo, uma vez que só poderia ser concretizada mediante a compressão da taxa de acumulação do capital. Ao tempo em que esta se reduzia para suas economias, os países da América Latina tornaram-se grandes exportadores de capital para os países credores (Batista, 1994).

Assim que a crise da inadimplência da dívida externa foi superada, mediante os acordos vinculados ao Plano Brady, a partir de 1988, a política latino-americana dos Estados Unidos orientou-se em sentido oposto. Passou a interessar ao governo norte-americano o aumento do seu superávit comercial com a América Latina, a fim de compensar, ao menos parcialmente, o déficit com outras regiões, atendendo também aos interesses das empresas exportadoras. Daí a recomendação aos países latino-americanos para o estímulo às importações, mediante redução drástica das barreiras tarifárias e não-tarifárias. Enfatizou-se a conveniência da liberalização do comércio exterior, entrando a globalização como argumento doutrinário, no contexto da teoria neoliberal. Mais uma vez, compreende-se a trajetória seguida por México, Argentina, Brasil e outros países da parte meridional do hemisfério. De um déficit de US\$ 11,2 bilhões no comércio com a América do Sul e o México, os Estados Unidos passaram, entre 1989 e 1992, para um superávit comercial da mesma ordem de grandeza (Batista, 1994).

Enquanto o Estado nacional, nos Estados Unidos, se mantém com o poderio inalterado, como Estado de uma superpotência, convém à sua estratégia que se enfraqueçam os dispositivos de intervenção, de controle e de regulamentação econômica de outros Estados nacionais; o que tem sido obtido, na América Latina, mediante adoção, pelos seus governos, de políticas consentâneas com a concepção neoliberal de subordinação irrestrita à dinâmica do mercado. É o caso, em especial, da política de desregulamentação do mercado da força de trabalho, sob o argumento de que a redução dos encargos sociais permitiria aumento do emprego. Argumento que se anula pelo contra-argumento de que a redução dos encargos sociais também torna menos dispendioso e mais fácil dispensar trabalhadores, ampliando o desemprego estrutural conseqüente das novas tecnologias.

A União Européia constitui, até agora, o único caso de associação de livre mercado que evoluiu para união aduaneira bem-sucedida. Tendo começado, em 
1958, com oito associados, hoje congrega 15 países. O livre trânsito de mercadorias, capitais e pessoas reduziu significativamente a função tradicional das fronteiras entre os partipantes do bloco, ensejando um entendimento supra-nacional inédito no continente europeu. Apesar disso, vem se revelando muito mais difícil do que o esperado a união política e monetária prevista no Tratado de Maastricht.

Dotada da economia mais poderosa, a hegemonia da Alemanha constitui um problema para os parceiros da União Européia. Enquanto a Alemanha procura firmar sua posição e atender às cautelas dos demais participantes do bloco, a estratégia da França, segunda nação mais forte, tem sido a de garantir uma posição de preeminência mediante aliança especial com a Alemanha, servindo de contrapeso a esta e oferecendo as ressalvas requeridas pelos países associados em favor do projeto de avanço da UE no sentido de degraus mais altos da unificação. Se a unificação objetiva o considerável aumento do poderio da UE como bloco, diante dos demais blocos e do mundo em geral, as posições da Alemanha e da França têm sido de se colocar no topo da nova UE em projeto. Com vistas aos ganhos estratégicos para o futuro, os Estados nacionais atuam como sujeitos da criação de uma entidade dentro da qual precisarão renunciar a aspectos valiosos de sua soberania. $\mathrm{O}$ apego a tais aspectos não parece suficiente para desaconselhar a adesão ao projeto evolutivo da unificação.

Por enquanto, a unificação conta com órgãos centrais de atribuições muito restritas diante dos governos de cada país associado. Semelhante ineficácia política poderia ser superada pela concretização dos passos previstos no Tratado de Maastricht, que deverá criar um governo da UE para questões atinentes à moeda única (com um Banco Central único), às relações exteriores e à defesa. No entanto, a execução do Tratado, aprovado em 1991, viu-se atropelada pela grave recessão iniciada quase ao mesmo tempo. As acentuadas oscilações cambiais e os déficits orçamentários excessivos logo mostraram a inviabilidade imediata das medidas previstas, determinando a dilatação dos prazos estabelecidos. As indicações apontam para um caminho longo com vistas ao objetivo fixado. De qualquer maneira, a UE tem feito e continuará a fazer o papel de projeto-piloto para os blocos existentes.

A UE dinamizou notavelmente o intercâmbio econômico dentro do seu âmbito, alçando-se a condições de concorrência com os Estados Unidos e o Japão. Seu discurso oficial em favor da liberalização não impede práticas protecionistas em setores específicos e diante de casos concretos. Assim é que aplicou medidas de proteção de sua agricultura diante das exportações agrícolas dos Estados Unidos e obrigou o Japão a adotar cotas voluntárias nas suas exportações de automóveis e de equipamentos microeletrônicos. Medidas protecionistas também são aplicadas no que se refere às exportações de commodities pela América Latina (Gazeta Mercantil, 1995:A-12). 
Os países da UE associaram, com êxito, graus variados de dirigismo estatal e de Estado do Bem-Estar ao processo de recuperação e de prosperidade no pósguerra. Os fundamentos da proteção social, construídos pelo Estado do BemEstar, apesar de restringidos ou abalados, ainda conseguem sobreviver diante da supremacia recente do neoliberalismo.

O Japão tornou-se potência industrial no segundo pós-guerra e, atualmente, é a segunda potência econômica mundial, em volume de produção. Tendo a devastação provocada pela Segunda Guerra Mundial como ponto de partida, o Japão alcançou a preeminência aplicando uma política que reúne as seguintes características principais:

- forte dirigismo estatal, que não inclui necessariamente a propriedade e gestão estatais de empresas;

- reserva do mercado interno para o capital nacional, de preferência mediante barreiras não-tarifárias (controles diversos que inviabilizam importações);

- forte concentração do capital, consolidando megacongleomerados com apoio financeiro do Estado;

- fomento vigoroso das exportações de produtos pertencentes a setores de máximo dinamismo e grande capacidade de alavancagem do conjunto da economia, com destaque para a microeletrônica e a indústria automobilística;

- contenção e remanejamento do movimento sindical, de maneira a manter um nível de salários, jornada de trabalho e outras condições compatíveis com as elevadas taxas de acumulação de capital;

- vigoroso impulso à educação generalizada e ao desenvolvimento da pesquisa científica e tecnológica (P\&D).

Sob ocupação norte-americana de 1945 a 1953, o Japão foi beneficiado pelo Plano Marshall e por outras iniciativas de apoio dos Estados Unidos, cujo governo objetivava afastá-lo de uma possível atração pela União Soviética e convertê-lo num sólido aliado contra esta; isso de fato aconteceu, sem que, no entanto, o Japão renunciasse à orientação soberana no concernente ao desenvolvimento econômico. Ao ganhar um aliado precioso no período da Guerra Fria, os Estados Unidos também contribuíram para erguer o rival mais capacitado à concorrência pela liderança econômica mundial.

Com a superioridade da sua produção em setores de ponta, o Japão tornou-se o segundo maior exportador (depois dos Estados Unidos e emparelhado com a Alemanha), acumulando seguidos superávits comerciais. Em particular, têm sido vultosos os superávits no intercâmbio com os Estados Unidos, motivando repetidas e pouco frutíferas pressões do governo norte-americano no sentido da redução substancial desse superávit. 
Com a valorização do iene, que lhe retira a vantagem cambial usufruída até há pouco, e diante das medidas protecionistas dos Estados Unidos e da UE, o capital japonês aumentou consideravelmente os investimentos externos. Estes implantaram-se nos territórios dos países desenvolvidos concorrentes, mas preferencialmente na área asiática. O capital japonês vem sendo um motor do dinamismo da economia do Extremo Oriente. A aliança entre Japão e China pode situar naquela região o pólo mais influente da economia mundial dentro das próximas duas décadas. Mas isso dependerá do êxito do projeto desenvolvimentista da China, também dominado pelo dirigismo estatal, e da maneira como a economia japonesa conseguirá superar a conjuntura atual de crise bastante grave.

Atingido pela recessão iniciada em 1991, o Japão apresentou um quadro de estagnação do crescimento econômico nos últimos três anos. Será obrigado a enfrentar problemas estruturais referentes ao custo elevado do capital e ao mercado financeiro, abalado pela excessiva expansão especulativa. Sua escalada futura está amarrada a soluções viáveis e de curto prazo para enfrentar tais problemas (Thurow, 1993; Thorstensen, 1992).

\section{Dependência e marginalização nas condições da globalização}

Os países atrasados ditos em desenvolvimento e também designados como países do Terceiro Mundo, têm as economias mais suscetíveis de debilitamento diante dos impulsos imprimidos à globalização pelas empresas multinacionais e pelo capital financeiro atuante no âmbito mundial. A fraca autonomia de decisões dos seus Estados nacionais é ainda mais reduzida, ou mesmo anulada, pelos fatores externos que procedem dos centros comandantes da economia mundial. Enquanto os Estados nacionais dos países desenvolvidos se valem da globalização para incrementar seu poder de influência interna e externa, os Estados nacionais dos países do Terceiro Mundo chegam ao limiar da impotência diante das flutuações dos mercados globalizados de investimentos financeiros, de bens e de serviços. Em conseqüência, são compelidos a adotar os rumos impostos pelo poder objetivo dos fatores externos.

Situação mais fragilizada do que a de dependência é, hoje, a da marginalidade. Na situação de dependência, ainda subsiste o vínculo que permite o relacionamento econômico com os países industrializados e a manutenção de atividades produtivas voltadas para o intercâmbio externo. Na situação de marginalidade, esse vínculo deixa de existir ou se torna mesquinho, forçando a retração de setores produtivos básicos.

A revolução tecnológica substituiu matérias-primas e insumos elaborados por novos materiais artificiais, muito mais eficazes, versáteis e baratos. Em geral, 
reduziu drasticamente a quantidade de insumos por produto final. A biotecnologia propiciou produtividade muito maior da agropecuária. Regiões antes importadoras de carne e cereais, como a Europa ocidental, hoje converteram-se em exportadores desses produtos

Tais resultados afetaram fortemente os países em desenvolvimento, exportadores de commodities. Os preços decrescentes os obrigam a vender maiores quantidades para obter receitas iguais, o que agravou sua dependência. Mas esta ainda é uma situação tolerável se comparada com a daqueles países que simplesmente perderam qualquer mercado para seus produtos tradicionais. São os países pertencentes à categoria dos marginalizados. Mais expostos à fome em massa, à miséria generalizada e às doenças epidêmicas, tais países se tornaram objeto de uma assistência internacional, capaz apenas de alívios emergenciais dos seus males. Assistência internacional que acorre com tanto maior presteza quanto mais risco oferecem os países marginalizados de se tornarem focos de pandemias e de migrações indesejáveis e incontroláveis para os países ricos.

A revolução tecnológica alargou consideravelmente a distância entre países desenvolvidos e países atrasados em matéria de ciência e tecnologia. Se a tecnologia característica da segunda revolução tecnológica se encontrava difundida e se tornara razoavelmente acessível aos países em desenvolvimento, já o mesmo, de modo algum, se dá com a tecnologia característica da revolução posterior, oram em curso. Esta se correlaciona com grandes investimentos em pesquisa científica, só factíveis aos governos dos países desenvolvidos e às empresas multinacionais. Demais disso, a concorrência acirrada entre megaorganizações impele à busca frenética de inovações tecnológicas cada vez mais freqüentes, o que, por sua vez, abrevia o prazo de vantagem econômica de tais inovações.

Nessas condições, tornou-se incomparavelmente mais difícil eliminar o fosso que separa países desenvolvidos de países atrasados. A superioridade tecnológica conferiu aos primeiros uma vantagem inapreciável. A carência tecnológica estabeleceu uma concorrência aguda entre os países atrasados pela atração de investimentos estrangeiros, que podem trazer embutidas as inovações pretendidas. Ainda que, comumente, os investimentos estrangeiros não tragam mais do que caixas pretas, vedando-se a difusão de conhecimentos que incrementam a autonomia técnica e econômica.

Dada a fraqueza de suas fontes de poupança interna, os países em desenvolvimento disputam entre si os investimentos externos, diretos e indiretos. Ocorre um verdadeiro leilão de concessões que servem de atração ao investimento estrangeiro. Contudo, parte considerável deste não tem sido mais do que capital especulativo aplicado em operações financeiras de curto prazo, com entradas e saídas motivadas por circunstâncias inteiramente ocasionais. 
O processo da globalização e da revolução tecnológica tem trazido, por conseguinte, o agravamento da desigualdade entre os países desenvolvidos e os países atrasados. Diminuir a desigualdade ou paralisar seu agravamento tornou-se, na fase em curso, tarefa extremamente árdua.

Para os Estados nacionais de países do Terceiro Mundo, a melhor estratégia possível, atualmente, parece ser a de garantir a sobrevivência. Projetos de desenvolvimento são, por isso, postergados para um futuro indefinido.

Não seria exagero afirmar que é isso que ocorre com os Estados nacionais da América Latina, inclusive mais destacadamente para os seus países maiores.

Ao começar a década dos 80, esses países viram-se subitamente premidos pela elevação acentuada das taxas de juros nos Estados Unidos. Suas dívidas externas, contraídas a juros flutuantes, sofreram súbito crescimento vertical. A crise da dívida externa tornou-se ainda mais penosa pela ocorrência simultânea de uma recessão mundial, trazendo consigo queda brusca dos preços das commodities. Tradução mais evidente de tal processo, a aceleração inflacionária alcançou, em alguns países, índices característicos de hiperinflação ou próximos deles.

A necessidade imperiosa de jugular a inflação conduziu aos planos de estabilização monetária. Sua aplicação, mesmo quando bem-sucedida no referente à redução do nível inflacionário, trouxe, em prazo maior ou menor, novos e acrescidos agravamentos da situação da grande maioria da população. Com exceção do Chile, o primeiro país no mundo a levar à prática o receituário neoliberal, os planos de estabilização, nos demais países da América Latina, ocasionam aquecimentos breves da economia, logo seguidos por contrações recessivas e taxas muito altas de desemprego. Sob suas lideranças atuais, esses países têm diminuída sua já fraca autonomia e se tornam crescentemente vulneráveis à pressão dos fatores externos.

A crise de dezembro de 1994 subverteu subitamente os fundamentos do plano de estabilização no México, reinstalando a espiral inflacionária e obrigando o governo a adotar medidas recessivas. Os créditos incontinenti fornecidos pelo presidente Clinton permitiram um respiro ao país, à custa da penhora de sua receita da exportação de petróleo e do controle de suas finanças pelo governo dos Estados Unidos

A crise mexicana refletiu-se na Argentina e no Brasil, impondo a ambos os países salvaguardas variadas. Se o Brasil vem recuando da abertura das importações, a Argentina procura manter a estabilidade monetária em condições de perturbações econômicas e deterioração da situação social. As medidas tomadas pelos governos dos dois países tornam inseguras as perspectivas de consolidação do Mercosul, tal qual ficou estabelecido nos acordos de Ouro Preto. 
O Brasil tem procurado implementar, no comércio exterior, uma estratégia de global trader. Encontra-se, contudo, limitado pelo fato de não contar, na sua pauta de exportações, com produtos competitivos nos setores tecnológicos de ponta, precisamente aqueles de maior incremento mundial (Velloso \& Fritsch, 1994; Thorstensen, 1994).

Casos especiais:

Coréia do Sul e Taiwan

A situação de dependência se auto-reproduz, configurando um círculo vicioso. Sem sair desse círculo, pode evoluir para uma situação de dependência associada, com algum tipo de desenvolvimento, conforme análise de variante menos mecanicista da teoria da dependência (Cardoso \& Faletto, 1970).

O círculo vicioso não é, porém, uma fatalidade. É possível que um país dependente consiga rompê-lo e ingressar no processo de desenvolvimento autônomo. A comprovação empírica dessa assertiva advém do fenômeno dos chamados tigres asiáticos, especialmente Coréia do Sul e Taiwan.

Em ambos os países, a liderança política autoritária adotou orientação antiliberal e impôs o dirigismo estatal à economia de mercado. Dessa maneira, os Estados nacionais tiraram proveito de circunstâncias favoráveis decorrentes da proximidade com o centro dinâmico japonês. Nos dois países, os influxos de capital estrangeiro - norte-americano e japonês - foram aproveitados com vistas ao aprendizado tecnológico e ao fomento de empresas nacionais, estatais e privadas. Semelhante orientação conduziu à economia fortemente estatizada, em Taiwan, ao passo que, na Coréia do Sul, levou à constituição dos chaebol - conglomerados privados possuidores de volumes de capital que os colocam na lista dos maiores do mundo.

Coréia do Sul, o país mais evoluído dentre os tigres asiáticos, logrou atingir capacidade competitiva e notável criatividade tecnológica graças a uma política consistentemente aplicada e que reúne determinados traços característicos. Assim, o governo da Coréia do Sul associou a reserva do mercado interno ao capital nacional com o incentivo estatal às exportações. A obrigação dos grupos privados nacionais de se exporem à concorrência internacional, através das exportações, evitou a tendência à estagnação tecnológica. Para o dinamismo tecnológico contribuiu também a escolha de incentivo aos setores com grande impulso de crescimento, como o microeletrônico, ou capacidade de alavancagem, como o automobilístico. O grande e continuado investimento estatal na educação generalizada permitiu formar uma força de trabalho de alta qualificação À medida que se elevavam os salários reais, a vantagem da compressão salarial pôde ser substituída pela vantagem da superioridade tecnológica associada aos preços competitivos. Comprova-o a penetração dos componentes e equipamentos 
microeletrônicos, bem como dos autoveículos sul-coreanos no mercado internacional, ao tempo em que o mercado interno do país permanece protegido e resguardado para a produção nacional (Canuto, 1994; Oliveira, 1992-1994, 1993).

Na tabela 5 , apresenta-se a evolução da produção automobilística mundial entre os anos 1979 e 1993. A produção sul-coreana teve o maior crescimento no período, com um aumento de $1000 \%$. Produção originária, vale salientar, de empresas privadas sul-coreanas.

Na tabela 6, mostram-se os volumes das exportações automobilísticas, no mesmo período, pelos países de maior destaque. Observa-se que a exportação sul-coreana cresceu em cerca de 1900\%, no intervalo de tempo analisado, enquanto a produção nacional praticamente eliminou a importação de autoveículos.

O patamar alcançado por Coréia do Sul e Taiwan ainda não permite considerar consolidado o desenvolvimento auto-sustentado, dotado de elevado grau de autonomia. Não obstante, é inegável que ambos os países puseram em prática estratégias que os colocam já bastante próximos de tal situação, característica de países desenvolvidos.

Tabela 1

Produto Interno Bruto - 1960/1992

Taxa de crescimento média anual (\%)

\begin{tabular}{|ccc|}
\hline Período & Mundo & $\begin{array}{c}\text { Países } \\
\text { Industrializados }\end{array}$ \\
\hline $1960 / 64$ & 4,94 & 4,94 \\
$1965 / 69$ & 4,96 & 4,88 \\
$1970 / 74$ & 4,14 & 3,62 \\
$1975 / 79$ & 3,80 & 3,12 \\
$1980 / 84$ & 2,40 & 1,86 \\
$1985 / 89$ & 3,82 & 3,36 \\
$1990 / 92$ & 2,53 & 1,50 \\
\hline
\end{tabular}

Fonte: FMI, Estadísticos financeiras internacionales, Anuário,1986 e 1994.

Obs: As médias anuais para PIB - mundo e países industrializados - são aritméticas e contêm erro não-significativo se comparadas com a média geométrica. 
Tabela 2

PIB a preços constantes em países da OCDE

Taxa média de variação anual (\%) - 1960/93

\begin{tabular}{|cccccccccccc|}
\hline \multicolumn{2}{|c}{ País } & & & & & & & & & \\
Período & EUA & Japão & $\begin{array}{c}\text { Bél- } \\
\text { gica }\end{array}$ & $\begin{array}{c}\text { Dina- } \\
\text { marca }\end{array}$ & França & $\begin{array}{c}\text { Alema- } \\
\text { nha }\end{array}$ & Itália & $\begin{array}{c}\text { Reino } \\
\text { Unido }\end{array}$ & $\begin{array}{c}\text { Espa- } \\
\text { nha }\end{array}$ & $\begin{array}{c}\text { Portu- } \\
\text { gal }\end{array}$ \\
\hline $1960 / 64$ & 3,76 & 11,34 & 5,42 & 5,48 & 6,24 & 7,14 & 6,90 & 3,70 & 7,70 & 6,08 \\
$1965 / 69$ & 4,20 & 10,28 & 4,28 & 4,20 & 5,20 & 4,24 & 5,82 & 2,58 & 6,68 & 6,54 \\
$1970 / 74$ & 2,50 & 5,94 & 5,12 & 2,60 & 4,68 & 3,44 & 4,42 & 2,70 & 6,04 & 7,26 \\
$1975 / 79$ & 3,18 & 4,44 & 1,98 & 2,48 & 2,72 & 2,06 & 3,42 & 2,16 & 1,62 & 3,54 \\
$1980 / 84$ & 1,84 & 3,48 & 1,44 & 1,72 & 1,46 & 1,00 & 1,72 & 0,84 & 1,28 & 1,24 \\
$1985 / 89$ & 3,12 & 4,52 & 2,56 & 2,00 & 3,10 & 2,64 & 3,12 & 4,02 & 4,26 & 4,22 \\
$1990 / 93$ & 1,50 & 2,55 & 1,18 & 1,20 & 0,90 & 1,80 & 0,90 & $-0,10$ & 1,40 & 1,24 \\
\hline
\end{tabular}

Fonte: FMI - Estadísticas financeiras internacionales, Anuário 1986 e 1994 e OECD - Main economic indicators, Mar. 1995.

Obs: Média aritmética das taxas de variação do PIB (a preços constantes) com relação ao ano anterior, o que superestima por pequena margem, à média geométrica.

Tabela 3

Produtividade do Trabalho no Setor de Negócios (a)

Taxa de Variação Anual (\%)

\begin{tabular}{|lccc|}
\hline & Período & & \\
País & $1960 / 73(\mathrm{~b})$ & $1974 / 79$ & $1980 / 91(\mathrm{c})$ \\
\hline EUA & 2,2 & 0,5 & 1,0 \\
Japão & 8,3 & 3,6 & 2,9 \\
Alemanha $(\mathrm{d})$ & 4,5 & 3,4 & 1,8 \\
França & 5,4 & 3,1 & 2,4 \\
Itália & 6,3 & 2,7 & 1,8 \\
Reino Unido & 3,6 & 2,3 & 2,2 \\
Canadá & 2,8 & 1,7 & 1,4 \\
\hline
\end{tabular}

Obs: $\quad$ (a) Produto por pessoa empregada (b) Reino Unido: 1961/73; França 1963/73; Canadá 1966/73 (c) Estados Unidos, Alemanha, França, Reino Unido: 1980/1992 (d) Alemanha Ocidental Fonte: OECD, Economic outlook, n. 54, dez. 1993 
Tabela 4

Produtividade Industrial

Taxa de Crescimento Médio do Produto por hora (\%)

\begin{tabular}{lcccccc|}
\hline & & & & & & \\
& & & & & & \\
País & $1960 / 70$ & $1979 / 75$ & $1975 / 80$ & $1980 / 85$ & $1985 / 90$ & $1990 / 92$ \\
\hline EUA & 2,65 & 2,83 & 1,77 & 4,14 & 2,73 & 3,10 \\
Canadá & 4,08 & 3,22 & 2,08 & 4,04 & 0,13 & 2,38 \\
Japão & 10,82 & 6,24 & 6,95 & 5,94 & 5,23 & 0,45 \\
Bélgica & 6,23 & 7,45 & 6,62 & 5,93 & 2,70 & 3,23 \\
Dinamarca & 5,84 & 7,59 & 3,49 & 1,05 & 0,47 & 1,34 \\
França & 6,70 & 4,92 & 4,56 & 3,76 & 3,29 & 1,37 \\
Alemanha & 5,86 & 4,82 & 3,81 & 3,45 & 2,05 & 1,70 \\
Itália & 7,46 & 4,62 & 5,11 & 4,63 & 2,90 & 3,52 \\
Países Baixos & 7,09 & 6,04 & 5,73 & 4,96 & 1,85 & 0,84 \\
Noruega & 4,11 & 3,45 & 1,97 & 3,25 & 2,16 & 1,27 \\
Suécia & 6,67 & 4,42 & 2,38 & 3,85 & 1,99 & 4,16 \\
Reino Unido & 3,70 & 3,37 & 1,41 & 5,76 & 4,50 & 4,38 \\
\hline
\end{tabular}

Fonte: Monthly Labor Review, abr.1988/mar. 1994. 
Tabela 5

Produção mundial de autoveículos

\begin{tabular}{|lrrrrr|}
\hline País & & & \multicolumn{3}{c}{ Em 1000 unidades } \\
\hline EUA & 1979 & 1980 & 1985 & 1990 & 1993 \\
Japão & 11.480 & 8.010 & 11.650 & 9.780 & 10.890 \\
Alemanha* & 9.636 & 11.043 & 12.271 & 13.487 & 11.228 \\
França & 4.250 & 3.879 & 4.446 & 4.977 & 3.991 \\
URSS & 3.613 & 3.378 & 3.016 & 3.769 & 3.156 \\
Coréia do Sul & 2.173 & 2.197 & 2.200 & 2.040 & 1.589 \\
Brasil & 1.128 & 1.165 & 967 & 915 & 1.391 \\
Total Mundial & 41.728 & 38.495 & 44.279 & 48.191 & 48.428 \\
\hline
\end{tabular}

* Até 1990, Alemanha Ocidental. A partir daí, Alemanha reunificada

** Até 1990, União Soviética. Em 1993, Comunidade dos Estados Independentes

Fonte: Anuário Estatístico da ANFAVEA, 1989, 1994

Tabela 6

Exportação de Autoveículos

\begin{tabular}{|lrrrrc|}
\hline & & & \multicolumn{3}{c}{ Em 1000 unidades } \\
\hline País & 1979 & 1980 & 1985 & 1990 & 1993 \\
\hline Japão & 4.563 & 5.967 & 6.730 & 5.831 & 5.018 \\
Alemanha* & 2.175 & 2.084 & 2.173 & 2.766 & 2.176 \\
EUA & 1.037 & 763 & 896 & 872 & 913 \\
França & 1.860 & 1.708 & 1.700 & 2.096 & 1.968 \\
Coréia do Sul & 31 & 25 & 124 & 347 & 639 \\
Brasil & 106 & 157 & 208 & 187 & 332 \\
\hline
\end{tabular}

* Até 1990, Alemanha Ocidental. A partir daí, Alemanha reunificada

Fonte: Anuário Estatístico da ANFAVEA, 1989, 1994 
Referências bibliográficas

Anderson, Perry. Balanço do neoliberalismo. In Pós-neoliberalismo. As politicas sociaise o Estado democrático. Emir Sader \& Pablo Gentili (orgs). Rio de Janeiro, Paz e Terra, 1995.

ANFAVEA. Anuário Estatístico. São Paulo, 1989, 1994.

BATISTA, Paulo Nogueira. O consenso de Washington: a visão neoliberal dos problemas latino-americanos. In: Em defesa do interesse nacional. Desinformação e alienação do patrimônio público. Barbosa Lima Sobrinho et al. Rio de Janeiro, Paz e Terra, 1994.

BOFF, Leonardo. Ecologia, mundialização, espiritualidade. A emergência de um novo paradigma. São Paulo, Ática,1993.

CANUTO, Otaviano. Brasile Coréia do Sul. Os (des)caminhos da industrialização tardia. São Paulo, Nobel, 1994.

CARDOSO, Fernando Henrique \& FALETTO, Enzo. Dependência e desenvolvimento na América Latina. Ensaio de interpretação sociológica. Rio de Janeiro, Zahar, 1970.

GAZETA MERCANTIL. São Paulo, 6 jun. 1995.

GILPIN, Robert. U.S. power and the multinational corporation. New York, Basic Books, 1975.

_. American policy in the post-Reagan era. New York, Dedealus, 1987.

GORENDER, Jacob. Marcino e Liberatore. Diálogos sobre marxismo, social-democracia e liberalismo. São Paulo, Ática, 1992.

IANNI, Octavio. A sociedade global. Rio de Janeiro, Civilização Brasileira, 1992.

NORONHA GOYOS Jr. Durval de. A OMC e os tratados da Rodada Uruguai. São Paulo, Observador Legal, 1994.

OLIVEIRA, Amaury Porto de. Coréia do Sul e Taiwan enfrentam o desafio da industrialização tardia. São Paulo, Estudos Avançados, v. 7, n. 17, São Paulo, IEA-UsP, 1993.

OLIVEIRA, Amaury Porto de. Cartas de Cingapura. São Paulo, IEA-USP, 1992-1994. passim.

ORTIZ, Renato. Mundialização e cultura. São Paulo, Brasiliense, 1994.

THORSTENSEN, Vera. Comunidade européia. A construção de uma potência econômica. São Paulo, Brasiliense, 1992.

THORSTENSEN, Vera; NAKANO, Ioshiaki et al. O Brasil frente a um mundo dividido em blocos. São Paulo, Nobel, 1994.

THUROW, Lester. Cabeça a cabeça. A batalha econômica entre Japão, Europa e Estados Unidos. Rio de Janeiro, Rocco, 1993.

VELLOSO, João Paulo dos Reis; FRITSCH, Winston et al. A nova inserção internacional do Brasil. Rio de Janeiro, José Olympio, 1994. 
VIGEVANI, Tullo et al. Realismo versus globalismo nas relações internacionais. São Paulo, Lua Nova, n. 34, 1994.

Resumo

Globalização e revolução tecnológica, que é a base material da primeira, trazem a possibilidade da futura sociedade planetária unificada. $\mathrm{Na}$ fase atual, a globalização ocorre como processo do capitalismo mundial e traz a tendência intrínseca 'a acentuação das desigualdades sociais e entre países, favorecendo os países desenvolvidos em detrimento dos atrasados. Diante deste processo, os Estados nacionais continuam a desempenhar papel de primeira importância, implementando estratégias relacionadas com suas posições econômica e geopolítica. A partir de tais premissas, são examinadas a constituição de blocos regionais; as estratégias dos Estados mais poderosos; a situação dos Estados dos países dependentes, com especial referência ao Brasil e aos países marginalizados; a emergência da área dinâmica do capitalismo no Extremo Oriente, com ênfase nos casos do Japão, da Coréía do Sul e de Taiwan.

\section{Abstract}

Not only globalization, but also technological revolution, which is the material basis of the former, bring about the possibility of a future unified planetary society. At the present state, globalization occurs as a process of wordwide capitalism and brings with it the intrinsic tendency to accentuate social unequalness among countries favoring developed countries to the detriment of undeveloped ones. Facing the process, the national Sates continue to perform a role of primary importance, implementing strategies related to its economic and geopolitical position. It is starting from such premises that we examine here the constitution of regional blocks; the strategies of the most powerful States; the situation of the dependent countries with special reference to Brazil and of the marginalized countries; the emergence of the dinamic area of capitalism in the Far East, with emphasis on Japan, South Corea and Taiwan.

Jacob Gorender, historiador, é professor visitante do Instituto de Estudos Avançados da UsP e autor de vários livros, entre eles O escravismo colonial e Combate nas trevas, ambos pela editora Ática.

Palestra feita pelo autor no IEA-USP em 13 de junho de 1995. O autor agradece ao professor Flávio Saes, da FEA-USP, pela elaboração dos quadros estatísticos das tabelas l a 4 . 